\title{
Estudo de caso: Engenharia Forense e a responsabilidade civil no desabamento de três edifícios no Rio de Janeiro
}

\author{
Case study: Forensic Engineering and civil responsibility in the collapse of three buildings in Rio de \\ Janeiro
}

Estudio de caso: Ingeniería Forense y responsabilidad civil en el colapso de tres edificios en Río de Janeiro

Recebido: 23/07/2021 | Revisado: 29/07/2021 | Aceito: 04/08/2021 | Publicado: 08/08/2021

\author{
Beatriz Costa de Mendonça \\ ORCID: https://orcid.org/0000-0001-6722-1711 \\ Universidade Federal Fluminense, Brasil \\ E-mail: biacm86@yahoo.com.br \\ Elie Chandan Mounzer \\ ORCID: https://orcid.org/0000-0003-1334-5975 \\ Universidade Federal Fluminense, Brasil \\ E-mail: emounzer@yahoo.con.br
}

\begin{abstract}
Resumo
A queda do edifício Liberdade, um prédio comercial de 20 andares, fez desabar também os dois prédios ao lado, os edifícios Colombo e Treze de Maio, localizados no Centro da Cidade do Rio de Janeiro. Inicialmente o prédio não apresentava causas aparentes que fizessem culminar em sua ruína e o foco se voltou para uma obra, irregular, realizada no $9^{\circ}$ andar. No decorrer do processo de responsabilização civil e penal, foram encontrados diversas causas que podem ter culminado no acidente. Mesmo com a realização de perícia judicial e os pareceres de diversos especialistas de engenharia, todos através de análise indireta, até a presente data não foi definida a causa do acidente. Entretanto, a responsabilização civil do síndico que permitiu diversas modificações no prédio no decorrer de décadas. A responsabilização em casos de acidentes pode recair sobre o engenheiro ou arquiteto da obra e, na ausência deste, sobre o proprietário ou síndico. O estudo conclui a importância da perícia direta em locais de acidentes, do papel da prefeitura e órgãos fiscalizadores e as mudanças nas normas infralegais relacionadas a obras e reformas após o acidente.
\end{abstract}

Palavras-chave: Responsabilidade civil; Laudo pericial; Edifício Liberdade.

\begin{abstract}
The fall of the Liberdade building, a 20-story commercial building, also caused the collapse of the two adjacent buildings, the Colombo and Treze de Maio buildings, located in downtown Rio de Janeiro. Initially, the building had no apparent causes that would lead to its ruin and the focus turned to irregular work carried out on the 9th floor. During the civil and criminal liability process, several causes were found that may have culminated in the accident. Even with the performance of judicial expertise and the opinions of several engineering specialists, all through indirect analysis, to date, the cause of the accident has not been defined. However, the civil liability of the manager allowed several modifications to the building over the decades. Liability in cases of accidents may fall on the engineer or architect of the work and, in his absence, on the owner or manager. The study concludes the importance of direct expertise in accident sites, the role of the city hall and inspection bodies, and the changes in infra-legal norms related to works and renovations after the accident.
\end{abstract}

Keywords: Civil liability; Expert report; Liberdade Building.

\section{Resumen}

La caída del edificio Liberdade, un edificio comercial de 20 pisos, también provocó el derrumbe de los dos edificios adyacentes, los edificios Colombo y Treze de Maio, ubicados en el centro de la ciudad de Río de Janeiro, el 25 de enero. Inicialmente, el edificio no tenía causas aparentes que lo llevaran a su ruina y el foco se centró en una obra irregular realizada en el noveno piso. Durante el proceso de responsabilidad civil y penal. Inicialmente, se discutieron varias posibles causas del accidente, a través de análisis indirectos. Incluso con la actuación de peritajes judiciales y las opiniones de diversos especialistas en ingeniería civil, hasta la fecha no se ha definido la causa exacta del accidente. Sin embargo, el administrador fue civilmente responsabilizado por el derrumbe y sus consecuencias por haber permitido varias modificaciones al edificio a lo largo de las décadas. Después de todo, la responsabilidad en casos de accidentes puede recaer en el ingeniero o arquitecto de la obra y, en su ausencia, en el propietario o gerente. 
El estudio concluye la importancia de la experiencia directa en los lugares de los accidentes, el papel del ayuntamiento y los órganos de inspección y los cambios en las normas infralegales relacionadas con las obras y renovaciones posteriores al accidente.

Palabras clave: Responsabilidad civil; Informe pericial; Edificio Liberdade.

\section{Introdução}

O edifício Liberdade foi originalmente construído com 18 pavimentos e 1 Subsolo, obtendo-se o habite-se junto a prefeitura municipal em 1940. É senso comum que as normas e a tecnologia evoluíram muito desde então, possibilitando a elaboração de cálculo estrutural através de softwares, trazendo diminuição de falha humana na etapa do projeto (Wang et al, 2018). No entanto, a engenharia é uma ciência exata e a necessidade do estudo de cargas e suas ações nas estruturas é fator basilar de qualquer projeto e atemporal. Embora projetado inicialmente para os 18 andares, na década de 1950, houve a expansão em planta dos 3 útlimos andares.

Soma-se ainda que durante a construção do metrô, em 1970. As obras subterrâneas influenciaram no edifício, fazendo-o descolar de seu prédio vizinho. No entanto, a obra monitorava minuciosamente a região e não ocorreram transtornos por esta razão, conforme informou o ex-diretor do metrô (Site Terra, 2012).

Logo após o acidente, a prefeitura iniciou a retirada dos escombros. Tal ação prejudicou a perícia, que teve que ser realizada de forma indireta, conforme indicado no laudo pericial elaborado pelo Instituto Carlos Éboli e a reportagem da BBC Brasil (2012). A perícia sem a observação direta da estrutura e de sua ruína não permite que sejam visualizadas características nos escombros que, possivelmente, elucidassem a causa do desabamento. Em que pese a observação e estudos forenses de forma indireta, a perícia realizada é capaz de identificar possíveis patologias que levaram à causa da ruína. Abaixo, é possível observar a partir de dois pontos distintos, o edifício que desabou - em vermelho - sobre os outros dois prédios vizinhos, o edifício Treze de Maio - em azul - e o edifício Colombo - em azul. (em amarelo e azul).

O Termo patologia é amplamente utilizado na medicina para designar um funcionamento anormal no organismo vivo. $\mathrm{Na}$ engenharia o termo tem significado similar. Aplica-se, genericamente, ao estudo de manifestações de falhas ou de deterioração da estrutura (Souza \& Ripper, 2009). Assim, a patologia das construções é o estudo de todo e qualquer problema que afete o desempenho da estrutura (Verçosa, 1991). Quando falhas acontecem, fica constatado que a estrutura patológica não atua como prevista em projeto, logo, não realiza a função para a qual foi criada (Feld \& Carper, 1997).

Nesse sentido, atua a engenharia diagnóstica e também busca estudar a causa e apresentar as patologias geradas que ocasionaram a um problema na edificação. O profissional de engenharia que busca as causas, no exercício das suas atividades com perito, deve ser capaz de realizar a identificação de falhas e a descrição dos fenômenos que levam ao problema na construção a um colapso de uma estrutura (Murphy, Duthie \& Bielert, 2010); (Ratay, 2009). Para a pericia atuar, não há a necessidade de que uma estrutura edilícia chegue a sofrer um colapso de grandes magnitudes. Para ser considerada uma falha estrutural, basta uma não conformidade com o que foi planejado e, consequentemente, um resultado não esperado. Em resumo, uma falha estrutural pode ser caracterizada por uma incompatibilidade entre o pretendido e o atual desempenho da estrutura (Nicastro, 1997); (Carper, 1987). Além disso, a análise pericial deve ser conduzida e pautada pela técnica, pela ética e pelo conhecimento (Shien et al, 2017); (Shnookal \& Shaw, 2011), pois tais estudos também são utilizados para orientar o juiz na sentença judicial (Ratay, 2011).

No que tange a responsabilização civil em razão de patologias e acidentes, a legislação brasileira prevê que o profissional de engenharia é responsável pela segurança e solidez da obra. No entanto, se não existir profissional de engenharia ou arquitetura contratado pelo proprietário do imóvel para realização de obras que impactem na estrutura da edificação, é o proprietário ou o síndico quem assume esta responsabilidade. 


\section{A Atuação do Engenheiro na Construção Civil}

No que tange às normativas específicas de construção, há diferentes normas com o intuito de melhorar a qualidade. Assim $_{2}$ estas definem os critérios de desempenho e de segurança para materiais e estruturas. As entidades internacionais mais utilizadas são as European standards (EM), American standards (ASTM) e a International Organization for Standardization (ISO) standards (Ingham \& Leek, 2016). No Brasil, além das normas internacionais, também são utilizadas as Normas Brasileiras (NBR), certificadas pela Associação Brasileira de Normas Técnicas (ABNT).

A normatização é uma excelente opção para o profissional utilizar, pois trará para a atividade a padronização necessária e, consequentemente, resultados controlados. Assim, não se fixa somente a experiência do engenheiro, e sim a todo profissional que queira atuar de forma eficaz e consonante ao seu objetivo (ABNT, 2006).

Neste sentido, é consenso entre diversos autores que o engenheiro perito, que atua com engenharia diagnóstica e forense, deve ter um sólido conhecimento técnico e experiência no campo de atuação, pois somente assim haverá uma análise pericial precisa e de qualidade (Heywood, 2011), (Thomaz, 1990), (Ratay, 2011).

Importa ressaltar a NBR 16.280/2014, que trata da reforma em edificações e que estas devem contar com a presença do profissional técnico para acompanhamento dos processos da obra. Esta norma traz padroniza as ações e processos em uma reforma, tendo em vista o envelhecimento as construções existentes, a perda da qualidade e segurança ao longo do tempo.

\section{Legislação aplicável}

Quando não são atendidas as normas técnicas, então os prejuízos de uma edificação com defeitos aparecem, ou seja, os vícios ocultos e as patologias, pode ser necessário recorrer ao Poder Judiciário se não houver uma solução amigável entre proprietário e construtor (Bell, 2000) (Ittmann et al, 2016).

No Brasil, o campo do direito a se socorrer é o civil, quiçá, o direito penal, se houver algum crime relacionado aos fatos. Com efeito, esse estudo se limita à abrangência da responsabilização civil de falhas ocorridas nas estruturas edilícias.

Neste sentido, extrai-se o fundamento, nos principais instrumentos normativos, tanto da Constituição da República Federativa do Brasil (1988) quanto do Código Civil (2002) e do Código de Processo Civil (2015). Neles, há artigos direcionados aos construtores, aos engenheiros e até mesmo aos proprietários que, ao não contratar um profissional especializado para a construção, passam a serem os responsáveis por quaisquer danos e acidentes que ${ }_{2}$ eventualmente ${ }_{2}$ possam ocorrer, se relacionados à construção ou à reforma.

Assim, para o presente tema, como principal destaque na legislação brasileira, o Código Civil (CC) traz, em seus artigos 186, 187 e 927, a definição de ato ilícito, quais sejam:

Art. 186. Aquele que, por ação ou omissão voluntária, negligência ou imprudência, violar direito e causar dano a outrem, ainda que exclusivamente moral, comete ato ilícito.

Art. 187. Também comete ato ilícito o titular de um direito que, ao exercê-lo, excede manifestamente os limites impostos pelo seu fim econômico ou social, pela boa-fé ou pelos bons costumes.

[...]

Art. 927. Aquele que, por ato ilícito (Arts. 186 e 187), causar dano a outrem, fica obrigado a repará-lo.

Parágrafo único. Haverá obrigação de reparar o dano, independentemente de culpa, nos casos especificados em lei, ou quando a atividade normalmente desenvolvida pelo autor do dano implicar, por sua natureza, risco para os direitos de outrem.

Logo, aplicam-se os referidos dispositivos quando ocorre um erro por parte do profissional, proprietário ou síndico. Já o artigo 927 leciona que o profissional que se enquadrar nos artigos 186 e 187 do CC 2002, deverá reparar o dano causado. Além disso, a jurisprudência da principal Corte infraconstitucional do país, o Superior Tribunal de Justiça (STJ), também 
regula o direito material. Durante muitos anos, orientado por ela, o prazo máximo para não se perder a pretensão de reparação do direito de obter do construtor uma indenização por defeitos da obra, conforme expresso pelo STJ na Súmula n 194 (1994), prescrevia em vinte anos. Contudo, esse prazo de prescrição da ação foi reduzido para dez anos com o advento do novo Código Civil de 2002 (art. 205). Assim, um engenheiro deve trabalhar de forma com que a construção não tenha problemas estruturais ao longo de dez anos, observando-se a devida manutenção ao longo da vida útil da estrutura.

\section{Responsabilidade Civil}

A responsabilidade civil é a obrigação que pode incumbir uma pessoa a reparar o prejuízo causado a outrem, por fato próprio, ou por fato de pessoas ou coisas que dela dependam (Rodrigues, 2006). Assim, a parte lesada envolve o juízo, em busca do responsável para o ressarcimento das patologias que, direta ou indiretamente, afetam a edificação.

Soma-se a isto que o responsável pela obra possui ainda a chamada responsabilidade objetiva. Nesta, há a responsabilização de quem deu causa ao problema, independentemente de culpa ou de dolo. Para tanto, basta a presença somente um nexo causal entre a conduta ilícita do indivíduo e a consequência por ela gerada, conforme o art. 927 do CC 2002 (Gagliano \& Pamplona, 2018, p. 380), (Tartuce, 2019, p. 819).

Pelo exposto, como se nota, no Brasil, o engenheiro ou o construtor pode ser responsabilizado pelas patologias que surgem na edificação e que foram ocasionadas por vícios ocultos na construção. Este tipo de problema é caracterizado quando um defeito não pode ser facilmente percebido a olho nu, mas irá aparecer definitivamente com o decorrer do tempo conforme expresso pelo STJ, no Agravo em Recurso Especial nº 1820955 (2021).

Assim, observa-se que, quando uma construção ou reforma apresenta falhas, inicialmente, em sede extrajudicial, há uma tentativa amigável de resolução do problema, por quem o causou, neste caso, pelo engenheiro ou pelo construtor. Estas podem ser feitas através de mediação ou de arbitragem. Se não for alcançada a solução através destes meios, o demandante ainda pode se socorrer do Poder Judiciário. Nele, busca-se_a análise do mérito da questão, ou seja, a atribuição da responsabilidade civil objetiva ou subjetiva do engenheiro sobre a obra (Jagannathan \& Delhi, 2019), (Fiker, 2011).

No Brasil, quando a opção é entrar com uma ação no Tribunal, o demandante deve, preliminarmente, provar que sofreu ato ilícito, enquadrados nos artigos 187 e 186 do código Civil, e peticionar em juízo, conforme o art. 319, IV do Código de Processo Civil (CPC). A parte ré é chamada para dar esclarecimentos nos autos do processo, podendo adotar a postura de negar todas as acusações. É nesse momento que, se a prova dos fatos depender de conhecimento técnico, o juiz nomeia um perito judicial para realizar a análise diagnóstica das patologias da edificação, seguindo a orientação do art. 156 c/c 375 do CPC 2015.

Ato contínuo, o perito então passa a desempenhar o papel de auxiliar da justiça. Nessa toada, atuando com imparcialidade (Confea, 2002), deverá analisar os fatos, principalmente, atuando in loco. Após, diante de suas conclusões, deverá emitir seu parecer. Uma vez que o perito apresente o laudo ao juiz, este poderá julgar o mérito da ação nos moldes do art. 479 da mesma lei. Em geral, quando apontado no parecer a sugestão de que houve tecnicamente um erro do profissional engenheiro ou construtor, o juiz acompanha referido parecer (Mendonça, 2021). A partir de então, o profissional responsável pela obra deverá efetuar o reparo material e/ou moral, conforme determinado na sentença. Dessa forma, é estabelecida em juízo a responsabilidade civil das patologias de edificações.

\section{O conteúdo do laudo pericial para a convicção do magistrado}

Teoricamente, o perito engenheiro só pode atuar no processo se comprovar experiência na área debatida nos autos e se estiver inscrito no Cadastro Eletrônico de Peritos e Órgãos Técnicos ou Científicos, conforme resolução do CNJ (2016). Em 
acordo com o art. 156, § $3^{\circ}$ e $5^{\circ} \mathrm{c} / \mathrm{c} 465$ do CPC 2015, é obrigatório ao engenheiro ter conhecimento teórico-técnico necessário para fazer a análise forense das questões a serem enfrentadas. Além disso, em decorrência, emitir um laudo pericial com as causas, as consequências, bem como registrar as metodologias utilizadas no estudo.

Nesta toada, a resolução no 345 do Conselho Federal de Engenharia e Agronomia (1990), define que a perícia é a atividade que envolve a apuração das causas que motivaram determinado evento ou da asserção de direitos. Isto posto, o engenheiro nomeado pelo juízo, portanto, um perito, é expert para realizar o parecer técnico tanto pelo Conselho de Engenharia, quanto pela Lei Civil. Para tanto, a legislação prevê os seguintes conteúdos dos laudos periciais, no artigo 473 do Código de Processo Civil:

I - a exposição do objeto da perícia;

II - a análise técnica ou científica realizada pelo perito;

III - a indicação do método utilizado, esclarecendo-o e demonstrando ser predominantemente aceito pelos especialistas da área do conhecimento da qual se originou;

IV - resposta conclusiva a todos os quesitos apresentados pelo juiz, pelas partes e pelo órgão do Ministério Público.

$\S 1^{\circ}$ No laudo, o perito deve apresentar sua fundamentação em linguagem simples e com coerência lógica, indicando como alcançou suas conclusões.

Em que pese a previsão da determinação legal, o perito é livre para confeccionar a escrita do seu laudo, afinal é o responsável por este (Fiker, 2019). Assim, não são todos os laudos que atendem de forma clara e objetiva a definição das causas dos vícios. De certo, cada laudo pericial traz consigo as suas peculiaridades. Afinal, o trabalho técnico pericial é o documento mais seguro que se vale o Magistrado para um pronunciamento firme sobre a pretensão deduzia em juízo (TJERJ, 2013).

Por conseguinte, o documento técnico em comento deverá prover o fundamento necessário para influenciar a convicção do magistrado na prolação da sentença. Afinal, em acordo com o inciso IX, do Art. 93 da Carta Magna, é nula a sentença sem fundamentação. Pode-se então o juízo realizar a fundamentação per relationem, isto é, com base na perícia, desde que o julgado faça a referência concreta ao laudo, inclusive, transcrevendo partes que julgar necessária (brasil, 2015).

\section{Metodologia Aplicada}

A metodologia aplicada adotou método científico de estudo de caso explanatório, conforme indicado pelo autor Yin (2001) processos judiciais neste país são públicos, salvo algumas exceções, conforme art. 189 do CPC 2015. O Poder Judiciário, para facilitar o acesso a qualquer interessado, mantém os processos em seu site virtual (TJERJ). Este estudo de caso é referente ao processo civil n ${ }^{\circ}$ 0072731-98.2014.8.19.0001, que tramitou na $10^{a}$ vara civil, do Fórum da Treze de Maio. Foram analisados todos os documentos acostados nos autos a fim de trazer ao presente estudo os ritos processuais e comprovações que resultaram na responsabilização civil e seus efeitos sobre os autores e réus da ação. O Instituto Carlos Éboli (ICCE) elaborou o laudo acolhido pelo magistrado para a sua convicção e prolação da sentença. O segundo laudo acostado é referente ao Engenheiro Gilberto Adib Couri, que foi apresentado pelos réus e traz uma visão extremamente divergente da apontada pelo ICCE, no entanto sem utilização ao longo do processo judicial, pelo juiz. Ambos os laudos foram debatidos neste estudo.

\section{Caracterização do estudo}

O desabamento do Edifício Liberdade chocou a cidade em janeiro de 2012, deixando 17 vítimas e 5 desaparecidos. O prédio era localizado em uma região administrativa na Avenida Treze de Maio, $\mathrm{n}^{\circ} 44$, Centro, Rio de Janeiro. Ao desabar, o 
prédio provocou o desabamento de mais dois prédios, o Ed. Treze de Maio e Ed. Colombo, além de danos ao Theatro Municipal, sendo esta uma edificação tombada pelo Instituto do Patrimônio Histórico e Artístico Nacional (IPHAN). Na análise deste caso concreto, verifica-se que o prédio possuía 20 andares e o terreno ocupava 20 metros de profundidade e 8,62 metros de largura, composto de lajes, pilares, vigas e caixa de elevador e acumulava diversas obras e modificações ao longo de sua vida útil. Em que pese haver o devido processo legal penal, o presente estudo versa sobre a responsabilidade civil em relação ao acidente, referente ao processo $\mathrm{n}^{\circ}$ 0072731-98.2014.8.19.0001. O proprietário do prédio também era o síndico, razão pela qual figura como responsável civilmente pelas causas do desabamento. Abaixo podem ser visualizados os prédios antes do desabamento.

Figura 1: Vista dos fundos do Teatro Municipal.

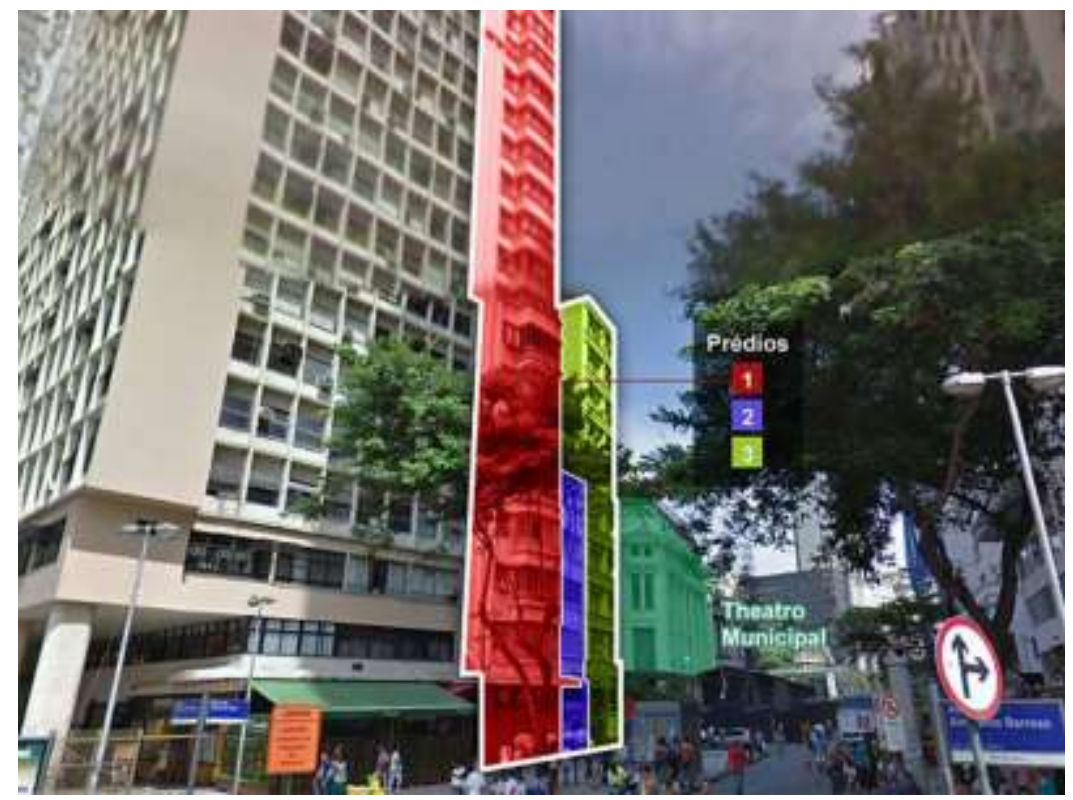

Fonte: (Terra, 2013).

Figura 2: Vista frontal do Teatro Municipal.

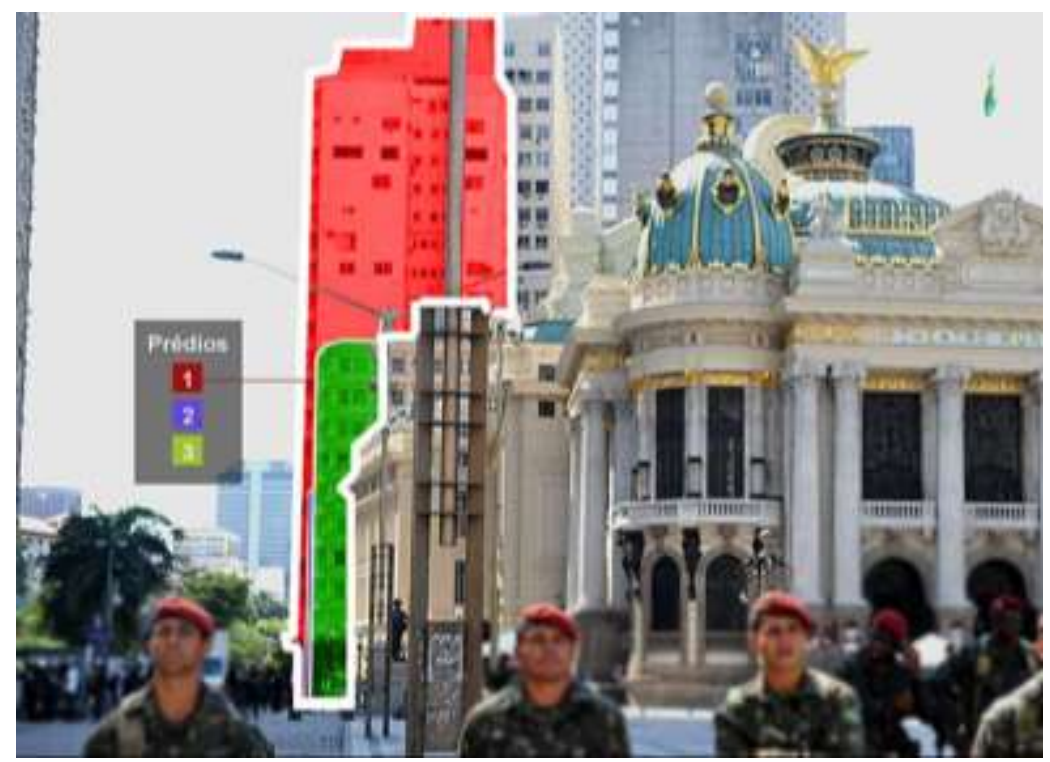

Fonte: (Terra, 2013). 
Segundo consta no laudo elaborado pelo ICCE, inicialmente o prédio foi projetado e legalizado junto à prefeitura, em 1938, para ter 16 pavimentos. No entanto, durante a obra, em 1939, foram acrescidos mais dois pavimentos, totalizando 18 andares e um subsolo. Os novos pavimentos superiores compunham a edificação em formato de escada, ou seja, não ocupavam toda a mesma área que os pavimentos originais, assim, o prédio passou a possuir a forma de um retângulo na sua fachada, conforme a figura, abaixo:

Figura 3. Diferenças entre a fachada do Edifício Liberdade.

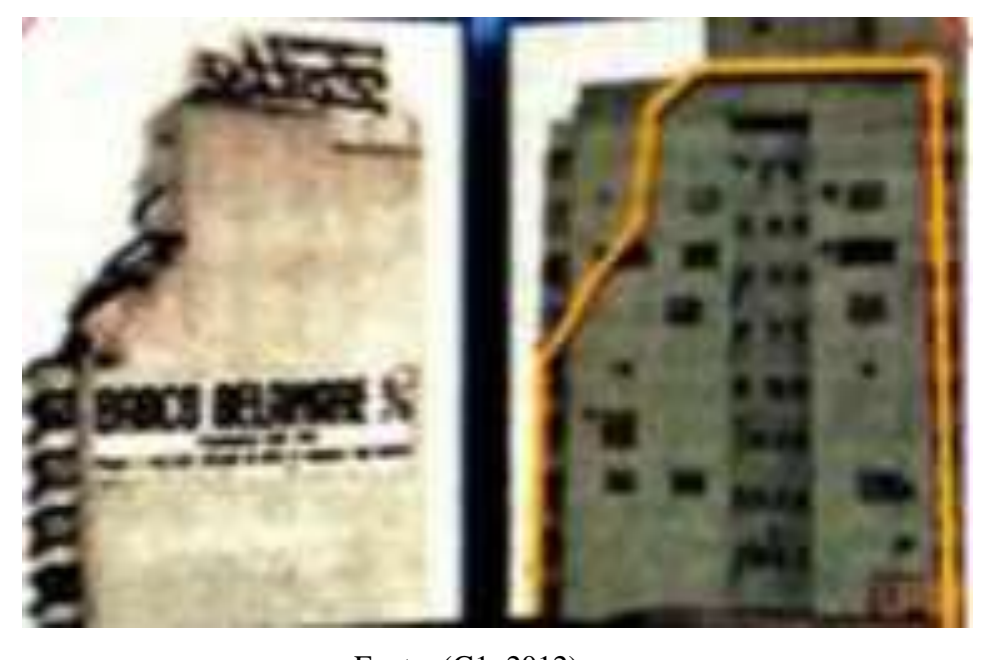

Fonte: $(\mathrm{G} 1,2012)$

A perícia não conseguiu apurar se o projeto estrutural acompanhou as modificações para suportar maior carga permanente. Um fato trazido por relatos, é que durante a escavação para a obra do metrô, na década de 1960, o edifício Liberdade apresentou um pequeno deslocamento em relação ao prédio vizinho. Neste sentido, acredita-se que não houve abalo da estrutura, além do relatado pelo diretor do metrô, à época, que toda a região foi monitorada durante as obras do metrô (Site Terra, 2012). A perícia realizou visitas aos prédios vizinhos ao desabamento, isto é, na área de influência do metrô e não encontraram indícios de danos em estruturas. O que restou constatado em visita ao terreno livre dos escombros é que o prédio possuía dez pilares e a parede contígua ao Ed. Treze de Maio (empena direita) e parte da fachada dos fundos eram em concreto armado e, portanto, com função estrutural. Constata-se então que todos os elementos estruturais verticais (pilares e paredes estruturais) eram no contorno das empenas. Quando comparada a foto antiga do prédio e a estrutura que desabou, pode-se verificar que a aparência tipo escada construída já não existia, pois o prédio já formava um retângulo perfeito. Não há registros de legalização deste acréscimo junto a prefeitura, bem como não há registro de reforço estrutural para tanto.

O ICCE utilizou a itemização dos assuntos para separar os assuntos dentro do laudo. Fato importante relatado pelos peritos do ICCE, está no item E12, que afirma diferença entre os pavimentos tipo. Do primeiro até o $8^{\circ}$ andar, todo o pavimento era livre. No entanto, do $9^{\circ}$ andar em diante, havia divisões em alvenaria que não há como saber se cumpriam alguma função estrutural. Há informação importante no item D1 do laudo, que mostra que originalmente, do $9^{\circ}$ andar para cima existia um prisma de ventilação na fachada esquerda. No item E13, a perícia acredita que o desabamento ocorreu por ruptura dos pilares da fachada esquerda. Há relatos que uma semana antes do desastre, apareceram fissuras diagonais nas paredes, e dificuldade de fechamento da porta do elevador, o que caracteriza problemas estruturais. É ressaltado que havia aberturas de janelas nas empenas laterais, o que demonstra que obras irregulares eram comuns já que isto não é autorizado pela prefeitura. Foi realizado ensaio não destrutivo nos pilares remanescentes, que restou comprovado que possuíam a resistência suficiente e dentro das normas da época. Também foi registrado que o aço utilizado era liso, ao invés das nervuras que 
promovem maior aderência. Entretanto, aquela era a forma permitida para a construção na época. Atualmente é sabido que as nervuras no aço tem importante papel na aderência aço-concreto (BAUER, 2018).

Em análise de vídeos ficou constado que as vigas possuíam mísulas, as quais desempenham função estrutural. Ao desabar, o edíficio Liberadade deixou ranhuras no edifício Capital, localizado a direita do Ed. Liberdade, a perícia conclui que o rompimento iniciou na metade da altura do Ed. Liberdade e carreou os edifícios a esquerda: Treze de Maio e Colombo.

O laudo pericial do ICCE, na parte da quesitação, traz o relato que várias pessoas presenciaram o início da ruptura no $9^{\circ}$ pavimento, o que faz o perito confirmar que a ruína pode ter iniciado neste andar (item L6). O perito também ratifica que qualquer obra deve ter acompanhamento de profissional de engenharia ou arquitetura, o que não ocorreu na obra do $9^{\circ}$ andar. No entanto, na análise dos documentos processuais, a empresa locadora do $9^{\circ}$ andar (TO Tecnologia) registrou que a obra não possuía profissional técnico, ficando a cargo da empresa que locava o andar acompanhar a obra, bem como definir o novo layout, já que não haveria alteração estrutural. O perito conclui seu laudo informando que ao longo do prazo ocorreu aumento de carga na edificação, somada as obras civis sem o devido acompanhamento do profissional técnico. Estes fatos tornaram a estrutura fragilizada. Por fim, o perito torna o laudo indeterminado devido à dinâmica do evento e a não análise dos escombros por retirada destes.

\section{Resultados e Discussão}

O processo $\mathrm{n}^{\circ}$ 0072731-98.2014.8.19.0001, iniciado em 2014, tem 5 (cinco) autores, todos proprietários do edifício Colombo, com 10 (dez) andares. Estes buscavam a responsabilização civil do proprietário de diversos pavimentos, incluindo o $9^{\circ}$ pavimento, que era locado por uma empresa e passava por obra sem responsável técnico. O proprietário do $9^{\circ}$ andar era também o síndico do prédio e tem o dever civil de permitir a realização de obras somente com o acompanhamento de engenheiro ou arquiteto. Em caso de não apresentação de profissional habilitado para o acompanhamento da obra, é dever do síndico notificar o responsável da obra e caso continue, denunciar aos órgãos de controle, por decorrência do art. 937 e 1.348 do Código Civil (2002). Assim, os autores buscam a reparação por danos materiais e morais devido à destruição total do Edifício Colombo, pela ruína do Edifício Liberdade. Os prédios eram vizinhos, conforme demonstra a Figura 4, abaixo:

Figura 4: Dinâmica do evento.

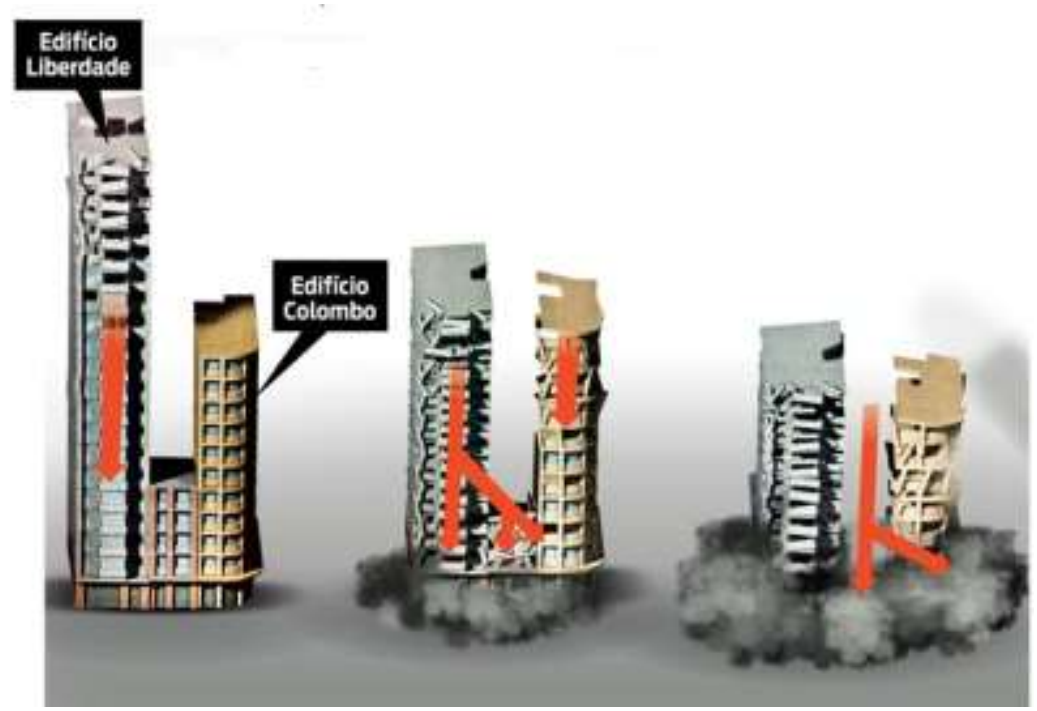

Fonte: (Revista Isto É , 2012). 
Na petição inicial, os autores trazem ao juízo a solicitação de indenização por danos materiais e morais. O primeiro se relaciona com os prejuízos físicos que ocorreram, e que impedem os autores de obter o lucro com os alugueis de todas as salas comerciais dos prédios. O segundo se relaciona com o fato do evento ter ocasionado aos proprietários do Ed. Colombo a lesão aos direitos da personalidade dos proprietários do imóvel, pois, de uma hora para a outra o prédio deixou de existir, sem que estes tivessem nenhuma oportunidade de impedir a tragédia.

Em que pese o laudo do ICCE ter sido o laudo acolhido para ser a perícia do processo alguns pontos poderiam ter sido esclarecidos no curso do processo judicial. Em casos de desabamento, é amplamente noticiado que são realizadas buscas aos escombros com a ajuda de cães e equipamentos para localizar vítimas e para peritos colherem indícios que dão causa ao acidente (Site G1, 2021). Esse trabalho é realizado principalmente nas primeiras 48h (Site Terra, 2018). No entanto, no presente caso concreto não ocorreu. Conforme consta nos autos, a remoção dos escombros foi imediata. Não se encontra a explicação de tal tratamento diferenciado. Inclusive, o laudo pericial traz expresso que não foi possível analisar os escombros, pois haviam sido retirados do local e por esta razão a perícia foi realizada de forma indireta. Esse formato de perícia é realizado quando o objeto é perdido, como no caso do presente estudo, na qual foram analisados documentos, imagens de câmera de segurança e prova testemunhal como base de emissão do laudo. Este tipo de perícia é plausível e pode ser considerado pelo magistrado para a sua conviç̧ão encontra respaldo inclusive no Superior Tribunal de Justiça (Brasil, Superior Tribunal de Justiça , 2020), embora não traga a riqueza de detalhes que uma perícia direta traz.

Os autores da ação sustentam a responsabilização objetiva e subjetiva do proprietário e síndico, com fulcro nos artigos 937 e 1348 do Código Civil (BRASIL, 2002), que permitiu a execução de obra no $9^{\circ}$ andar sem a presença de profissional técnico responsável. No entanto, a empresa que locava o andar declarou que a reforma não atingiria questões estruturais, razão pela qual não se tinha profissional habilitado na obra. Neste ponto é nebulosa a questão entre o síndico e o locador do pavimento, pois somente um profissional de engenharia e arquitetura poderia concluir que remover paredes afetaria ou não a estrutura.

Há de trazer ainda a questão da legalização junto aos órgãos de controle, que neste caso, são a prefeitura municipal e os Conselhos de Engenharia e Agronomia (Confea) e de Arquitetura e Urbanismo (CAU). É de ciência comum que obra necessita de autorização dos órgãos competentes. No entanto, quando não é legalizada a obra, qual o papel dos órgãos de controle ? Qual o impacto real da fiscalização da prefeitura junto as edificações do município. Tem-se uma fiscalização passiva, atuante somente em casos de denúncia de terceiros. Não obstante, a lei Estadual 6400/2013 instituiu a obrigatoriedade da autovistoria predial. Posteriormente, a NBR 16.280/2014, traz a necessidade de apresentação de projeto de reforma, elaborado por profissional habilitado, com comunicação formal ao responsável da edificação e aprovação deste antes do início das obras. Estes fatos comprovam que à época do acidente, em que pese já existir dispositivo legal neste sentido, havia uma necessidade de melhor regulação neste sentido. Em contradição à melhor regulação de obras e reformas, o município habitualmente promulga lei complementar conhecida como "lei do puxadinho", na qual as regras urbanísticas são flexibilizadas e, na prática, qualquer edificação que desrespeitasse as normas municipais, seriam aprovadas mediante pagamento à prefeitura. A última lei neste sentido, a Lei Complementar 219 de 2020 é razão de suspensão pelo STF em razão dos impactos negativos de recorrentes aprovações de obra irregular.

Por outro lado, os réus argumentam que a empresa que locava o $9^{\circ}$ andar era a única responsável pela obra em comento e que houve rompimento de peças estruturais durante a obra, o que seria a causa do desabamento. Dessa forma, o réu imputa o fato a terceiro, o que descaracterizaria a responsabilidade objetiva sobre o evento, isto é, excluindo o nexo de causalidade.

Os réus solicitaram produção de prova pericial de engenharia, documental e testemunhal. Somente o primeiro foi negado. O magistrado acolheu o laudo do ICCE como o laudo pericial para a sua convicção e prolação da sentença. Em que 
pese o tribunal, na sentença e no acórdão emitido em dezembro de 2019, rejeitar a produção de prova pericial de engenharia no curso da ação proposta, promovendo a convicção no laudo pericial já elaborado (BRASIL, 2017), (BRASIL, 2014) as informações trazidas no parecer apresentado pelo réu é de extrema relevância, pois traz todas as hipóteses possíveis e as consequências de cada uma delas.

O parecer foi emitido por engenheiro e arquiteta com vasta experiência em engenharia pericial e trazem uma visão embasada tecnicamente que refutam as teorias até então levantadas e demonstra, cabalmente, que a causa do desabamento se deu por supressão de elemento estrutural durante a obra no $9^{\circ}$ pavimento. O parecer recebeu, inclusive, menção honrosa em apresentação no XVII congresso nacional de avaliação e perícia, em 2013 (COURI, 2013). Os profissionais demonstram através de maquete eletrônica que, ao considerar que o prisma de ventilação era composto por pilares que nasciam nas vigas do $8^{\circ}$ andar, a dinâmica do evento é compatível com a constatada na perícia. Concluem ainda que os acréscimos feitos, não poderiam acarretar décadas depois uma ruína repentina. Os autores trazem ainda a exclusão de outras possíveis causas, como a obra do metrô na década de 1970 e o comprometimento do solo por este ter sido aterrado na década de 1930. Traz-se ainda a questão dos acréscimos de carga permanente sofrida pela edificação ao longo dos anos o que não alterou a estabilidade da estrutura. O parecer é claro em afirmar que somente algo com impacto extremo causaria a ruína de um prédio que se apresentava estável e sem sinais de deformação e recalques após as possíveis causas elencadas.

Neste sentido, há de ressaltar que o laudo referido acima, foi, por óbvio realizado após o desabamento e possui riqueza de detalhes muito superior ao laudo elaborado pelo ICCE, pois são apresentadas as refutações passo a passo, com o devido embasamento técnico. Em divergência ao laudo inconclusivo do ICCE, o parecer é enfático na demonstração de que havia pilares de sustentação dos prismas de ventilação que existiam do $9^{\circ}$ pavimento para cima. Ali nasciam pilares nas vigas do teto do $8^{\circ}$ andar. No entanto, por acreditar que não havia prisma no $9^{\circ}$ andar, por este ter sido fechado e não regularizado junto à prefeitura, a empresa removeu todas as paredes, o que incluiria os pilares descarregavam toda a carga do prisma, para a viga do $8^{\circ}$ andar.

Ao desconsiderar a visão do parecer, bem como negar a produção de nova prova pericial, o magistrado acolhe na sentença a fundamentação da responsabilidade objetiva e subjetiva do síndico e proprietário do imóvel, o qual não atuou em acordo com seu dever, de promover as obras do prédio devidamente legalizadas junto a prefeitura, bem como quaisquer alterações de layout que impactassem na estrutura, como ocorreu no fechamento do $9^{\circ}$ pavimento.

Assim, o juízo entende que é o síndico e também proprietário é totalmente responsável civilmente pelos danos causados aos proprietários do Ed. Colombo. Não há dúvidas quanto a isso na fundamentação da sentença e esta se mantém no acordão proferido em 2018, na qual os desembargadores permanecem a negativa de produção de novas provas periciais, o que poderia elucidar melhor o caso uma vez que tanto na primeira perícia quanto na segunda, seriam realizadas de forma indireta.

\section{Conclusão}

O desabamento do edifício Liberdade em 2012 resultou em melhor apontamento das responsabilidades do síndico e proprietário de imóvel, devido a promulgação da lei estadual de autovistoria n $6400 / 2013$ e a NBR NBR 16.2018/2014, que estabelece a necessidade de emissão de laudo de reforma por profissional habilitado.

Embora possa existir fato de terceiros que levem a um acidente de engenharia, a responsabilidade civil objetiva do proprietário de uma edificação não é refutada se este não cumprir com o seu dever legal de zelar pela edificação e condomínio.

A prefeitura deve exercer de forma rotineira a vistoria de edificações no município a fim de autuar obras ilegais e fora dos padrões urbanísticos.

A retirada de escombros de obras de desabamentos deve encontrar o perfeito equilíbrio entre busca de vítimas e verificação pericial, devido ao risco de perda do poder de investigação forense e, consequentemente, perícia conclusiva. 
Com a verificação das principais causas que levam um edifício a ruína, bem como a responsabilidade civil das partes envolvidas, é possível realizar a conscientização de que não necessariamente quem está ligado diretamente com uma obra, executando ela de fato será o responsabilizado civilmente.

Estudos de caso similares são encorajados a fim de averiguar o padrão de autoridades e pessoas relacionados à responsabilidade civil em acidentes de engenharia.

\section{Referências}

$A B N T$. (s.d.). Associação Brasileira de Normas e Técnicas: http://www.abnt.org.br

ABNT. (2006). Guia 2:2006. ABNT.

ABNT. (2014). NBR 16.280: Reformas em edificações - Sistema de gestão de reformas - Requisitos.

ABNT. (2014). NBR 6118: Projeto de estruturas de concreto - Procedimento.

Bauer, F. (2018). Materiais de Construção. LTC.

BBC Brasil. (2012). Dois meses depois de desabamento no Rio, inquérito segue sem previsão de encerramento: https://www.bbc.com/portuguese/noticias/2012/03/120324_desabamentos_rio_dois_meses_jc

Bell, G. (2000). Engineering investigation of structural failures. In: R. Ratay, Forensic Structural Engineering Hankbook (pp. 6.2 - 6.4). Mc Graw-Hill. Brasil. (1988). disponível em Constituição da República Federativa do Brasil: http://www.planalto.gov.br/ccivil_03/constituicao/constituicaocompilado.htm Brasil. (1990). Conselho Federal da Engenharia e Agronomia. disponível em Resolução nº 345: http://normativos.confea.org.br/downloads/0345-90.pdf Brasil. (1994). Superior Tribunal de Justiça. 194: https://scon.stj.jus.br/SCON/sumstj/toc.jsp?livre=194\&tipo=sumula+ou+su $\& \mathrm{~b}=$ SUNT $\&$ thesaurus $=$ JURIDICO\&p=true

Brasil. (2002). Lei $n^{\circ}$ 10.406. disponível em Código Civil: http://www.planalto.gov.br/ccivil_03/_Ato2015-2018/2015/Lei/L13105.htm

Brasil. (2014). Superior Tribunal de Justiça. Fonte: AREsp 336.893-SC.

Brasil. (2015). Lei $n^{o}$ 13.105. disponível em Código de Processo Civil: http://www.planalto.gov.br/ccivil_03/_Ato2015-2018/2015/Lei/L13105.htm

Brasil. (2015). Superior Tribunal de Justiça. disponível em HC 214049-SP. $6^{\circ}$ turma.

Brasil. (2016). Conselho Nacional de Justiça. disponível em Resolução nº 233: https://atos.cnj.jus.br/atos/detalhar/atos-normativos?documento=2310

Brasil. (2017). AResp 1011318/ES. Superior Tribunal de Justiça.

Brasil. (2020). Superior Tribunal de Justiça . Fonte: AgRg HC 610287/MS.

Brasil. (2021). Superior Tribunal de Justiça. disponível em AREsp no 1820955: https://scon.stj.jus.br/SCON/decisoes/toc.jsp?livre=182095 $5 \& \mathrm{~b}=\mathrm{DTXT} \& \mathrm{p}=$ true

Carper, K. (04 de 1987). Structural Failures During Construction. Journal of Performance of Constructed Facilities, pp. $132-144$.

Confea. (2002). Conselho Federal de Engenharia e Agronomia. Código de Ética do Profissional da Engenharia, da Agronomia, da Geologia, da Geografia e da Meteorologia: https://www.confea.org.br/codigo-de-etica-2\#: :text=A\%20\%C3\%A9tica\%2C\%20como\%20define\%20o,abrangidas\%20pelo\% 20Sistema $\% 20$ Confea\%2FCrea.

Couri, G. A. (2013). XVII Congresso Brasileiro de Engenharia de Avaliaçãoes e Perícias. Acesso em 10 de jul de 2021 , disponível em Trabalhos Premiados: https://www.cobreap.com.br/2013/trabalhos-premiados.html

Feigelson, S. (2016). Perícias de Engenharia. A Apuração dos Fatos (3a ed.). Leud.

Feld, J., \& Carper, K. (1997). Construction Failure. John Wiley, Inc. .

Fiker, J. (2011). Perícias e Avaliações de Engenharia. Fundamentos Práticos (2a ed.). Leud.

Fiker, J. (2019). Manual de Redação de Laudos (3a ed.). Oficina do Texto.

G1. (2012). Projeto de prédio que desabou não é encontrado nos arquivos da prefeitura: http://g1.globo.com/rio-de-janeiro/noticia/2012/02/projeto-de-predioque-desabou-nao-e-encontrado-nos-arquivos-da-prefeitura.html

Gagliano, P. S., \& Pamplona, R. (2018). Novo Curso de Direito Civil (17a ed.). Saraiva Jur.

Gomide, T. (2016). Engenharia Diagnóstica em Edificações. 
Research, Society and Development, v. 10, n. 10, e216101018648, 2021

(CC BY 4.0) | ISSN 2525-3409 | DOI: http://dx.doi.org/10.33448/rsd-v10i10.18648

Heywood, R. (2011). Responding to failure: an introduction to forensic structural engineering. Australian Journal of Structural Engineering, pp. 1-10.

Ingham, J., \& Leek, D. (2016). Forensic engineering of construction materials: lessons learnt from disputes. Forensic Engineering, 33-44.

Ittmann et al. (03 de 2016). Personal Liability of the Practicing Engineer. Journal of Legal Affairs and Dispute Resolution in Engineering and Construction.

Jagannathan, M., \& Delhi, V. (2019). Litigation in Construction Contracts: Literature Review. Journal ofLegal Affairs and Dispute Resolution in Engineering and Construction.

Mendonça, B. C. (27 de abr de 2021). Responsabilidade civil nas patologias de edificações: uma visão técnica sobre as perícias judicias. Brazilian Journal of Development, 7 , https://doi.org/10.34117/ bjdv7n4 623.

Murphy, P., Duthie, L., \& Bielert, B. Australian Journal of Structural Engineering. Australian legal guidelines for forensic engineering, pp. p. 11-22.

Nicastro, D. (1997). Failure Mechanismin build construction. ASCE Press.

Ratay, R. (05 de 2009). Forensic structural engineering practice in the USA. Proceedings of the Institution of Civil Engineers - Civil Engineering, pp. 52-56.

Ratay, R. (5 de 2011). The forensic structural expert consultant/witness - US practices. Forensic Engineering, pp. 79-86.

Revista Isto É . (2012). Acesso em 21 de 07 de 09, disponível em O preço da imprudência: https://istoe.com.br/188471_O+PRECO+DA+IMPRUDENCIA/ Rodrigues, S. (2006). Direito Civil (20ª ed., Vol. 4). São Paulo: Saraiva.

Shien, N. G., et al. (03 de 2017). Teaching Forensic Engineering in Civil Engineering. Journal of Performance of Constructed Facilities.

Shnookal, B., \& Shaw, J. (2011). The ethics of forensic engineers. Australian Journal of Structural Engineering.

Site G1. (2021). Desabamento de prédio na região de Miami: o que se sabe e o que falta saber: https://g1.globo.com/mundo/noticia/2021/06/25/desabamentode-predio-na-regiao-de-miami-o-que-se-sabe-e-o-que-falta-saber.ghtml

Site Terra. (2012). Ex-diretor nega que obras do metrô influenciaram desabamento: https://www.terra.com.br/noticias/brasil/cidades/ex-diretor-nega-queobras-do-metro-influenciaram-desabamento,5798c280d01da310VgnCLD200000bbcceb0aRCRD.html

Site Terra. (2018). Cães farejadores não encontram vítimas em prédio que desabou : https://www.terra.com.br/noticias/brasil/cidades/caes-usados-na-buscaem-predio-de-sp-que-desabou-nao-encontram-vitimas,d7bb394e14efd4932b48f2f7836797dfgj3bff8k.html

Souza, V., \& Ripper, T. (2009). Patologia, recuperação e reforço de estruturas de concreto. Pini.

Tartuce, F. (2019). Direito Civil. Direito das Obrigações e Responsabilidade Civil (14a ed.). Forense.

Terra. (2013). Justiça começa a ouvir envolvidos na queda do Edifício Liberdade: https://www.terra.com.br/noticias/brasil/cidades/rio-justica-comeca-a-ouvirenvolvidos-na-queda-do-edificio-liberdade,7d69be73d11e1410VgnCLD2000000dc6eb0aRCRD.html

Thomaz, E. (1990). Patologia. ABCI.

TJERJ. (2013). Acordão Processo n ${ }^{o}$ 0030222-71.2013.8.19.0007. Tribunal de Justiça do Estado do Rio de Janeiro. 2ª instância, Rio de Janeiro.

TJERJ. (s.d.). Tribunal de Justiça do Estado do Rio de Janeiro. http://www.tjrj.jus.br/

Toit, J. (November de 2012). Ethics as commodity in higher education of South African natural science and engineering students. Koers Journal, pp. 1-8.

Verçosa, E. (1991). Patologia das Edificações. Sagra.

Verrax, F. (2017). Engineering ethics and post-normal science: A French perspective. Futures, pp. 76-79.

Wang et al. (2018). Research on Optimization of Big Data Construction Engineering Quality Management Based on RNN-LSTM. Complexity Problems Handled by Big Data Technology.

Yin, R. (2001). Estudo de caso. Planejamento e Métodos. (2a ed.). Bookman. 